\title{
Modificación de forma de corona clínica
}

\section{Clinical crown shape modification}

\author{
Jaime Bárcena Taco ${ }^{\text {1a }}$, Alejandro Aldana Cáceres ${ }^{2 b}$ \\ ${ }^{1}$ Escuela de Odontología de la Universidad Nacional Jorge Basadre Grohmann. \\ ${ }^{2}$ Escuela de Odontología de la Universidad Nacional Jorge Basadre Grohmann. \\ ${ }^{a}$ Docente, Magister en Docencia Universitaria y Gestión Educativa. \\ ${ }^{\mathrm{b}}$ Docente, Doctor en Ciencias de la Salud.
}

\begin{abstract}
Resumen
El presente reporte de caso tiene como objetivo principal presentar una técnica con abordaje quirúrgico mínimamente invasivo para la modificación de la forma de la corona clínica y del tejido de adherencia supracrestal del incisivo lateral y canino izquierdo. Se sustentó el procedimiento a partir de la revisión de evidencia científica que validó la técnica utilizada en la resolución del presente caso. El resultado obtenido fue satisfactorio y cumplió las expectativas de la paciente. La técnica quirúrgica mínimamente invasiva demostró resultados previsibles quirúrgicamente y satisfactorios estéticamente para el paciente.
\end{abstract}

Palabras clave: Espacio biológico, modificación de forma de corona, tejido de adherencia supracrestal, osteotomía.

\begin{abstract}
The main objective of this case report is to present a technique with a minimally invasive surgical approach for the modification of the shape of the clinical crown and the supracrestal adhesion tissue of the lateral and left canine incisors. The procedure was based on the review of scientific evidence that validates the technique used in the resolution of this case. The result obtained was satisfactory and met the patient's expectations. The minimally invasive surgical technique demonstrated results that were expected surgically and aesthetically satisfactory for the patient.
\end{abstract}

Keywords: Biological space, crown shape modification, supracrestal adhesion tissue, osteotomy.

\section{Introducción}

La estética es una necesidad primordial en todos los tratamientos que se desarrollan en la actividad odontológica, y ciertamente el paciente busca la alternativa que le permita satisfacer esta necesidad, pese a que muchas veces las condiciones que se presentan no son las óptimas y tienen limitaciones que el profesional debe poder resolver de la mejor manera. Es entonces que la cirugía periodontal puede ayudar a dar una solución que pueda ser la que cumpla las expectativas del paciente (1).
El alargamiento de corona fue propuesto inicialmente por Cohen (1962), y consiste en una técnica quirúrgica que a partir de la modificación de los tejidos duros y blandos en el entorno de la pieza dentaria logra incrementar la altura de la corona clínica o modificar la forma de la misma $(2,3)$.

La técnica quirúrgica considera prioridad respetar la integridad de la pieza dentaria, tratando de preservar los tejidos de soporte conservando el espacio biológico hoy denominado soporte supraóseo, considerando la buena adaptación de la restauración y 
una estética adecuada (4).

El tejido de adherencia supracrestal llamado antes espacio biológico es definido como la suma de las fibras supracrestales y de la inserción epitelial, es decir, la dimensión de la unión conectiva a la raíz sumado a la dimensión de la inserción epitelial y a la profundidad del surco gingival $(4,6)$.

La denominación de espacio biológico fue sustentada en el trabajo de Gargiulo (1961), que describe la dimensión y relación de la unión dentogingival en humanos: profundidad de surco de $0.69 \mathrm{~mm}$, adherencia epitelial de $0.97 \mathrm{~mm}$, inserción del tejido conectivo de $1.07 \mathrm{~mm}$, dando un total para ancho biológico de $2.04 \mathrm{~mm}$. $(1,4,7,9)$.

La distancia mínima de $3 \mathrm{~mm}$ debe estar presente entre el margen de la restauración y el hueso alveolar para evitar se genere una invasión de este espacio con la consecuente lesión de estas estructuras $(7,10,11)$.

\section{Caso clínico}

Paciente femenino de 24 años acude a consulta por presentar un aspecto que le desagrada en sus dientes antero superiores, refiere que estuvo en tratamiento de ortodoncia previo por aproximadamente 3 años y no desea un nuevo tratamiento. Asimismo, le preocupa la forma de sus dientes y espera pueda corregir el aspecto de ellos y mejorar su sonrisa. A la anamnesis no refiere antecedentes patológicos o de otra índole que deba considerarse.

Del examen clínico, se evidencia la ausencia de la pieza 1.1 y alteración de la línea media, sin espacios entre las piezas presentes (Figura 1). Al análisis radiográfico se confirma la ausencia de la pieza 1.1 (Figura 2). Al sondaje no se evidencia presencia de bolsas periodontales. Además, refiere que no desea un nuevo tratamiento ortodóncico.

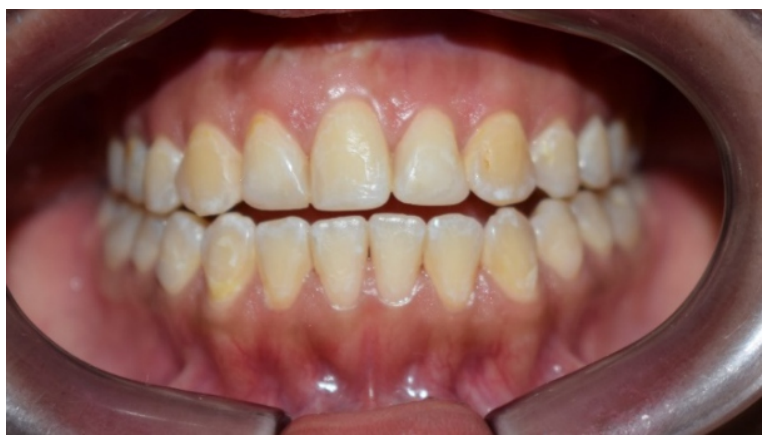

Figura 1. Ausencia de la pieza 1.1 y alteración de la línea media.

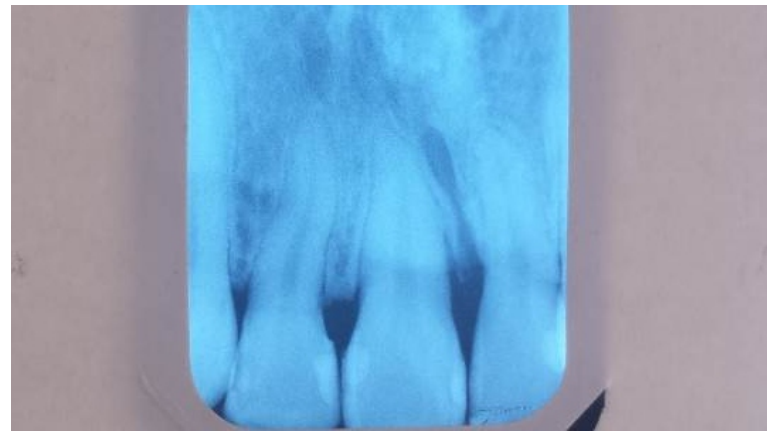

Figura 2. Radiografía periapical

Se propone un tratamiento lo menos invasivo posible, a partir de un mockup en el modelo de yeso (Figura 3) el cual con ayuda de una guía de silicona y resina bisacril es llevada a boca, ante la propuesta, la paciente acepta la forma obtenida con el mockup (Figura 4), por lo que el plan de tratamiento que acepta es una modificación de corona clínica con alteración de la forma en la pieza 2.1 como ICD, la 2.2 para compensar la forma del ICI y la pieza 2.3 la correspondiente al ILI. Se confecciona entonces una guía quirúrgica en una lámina de acetato.

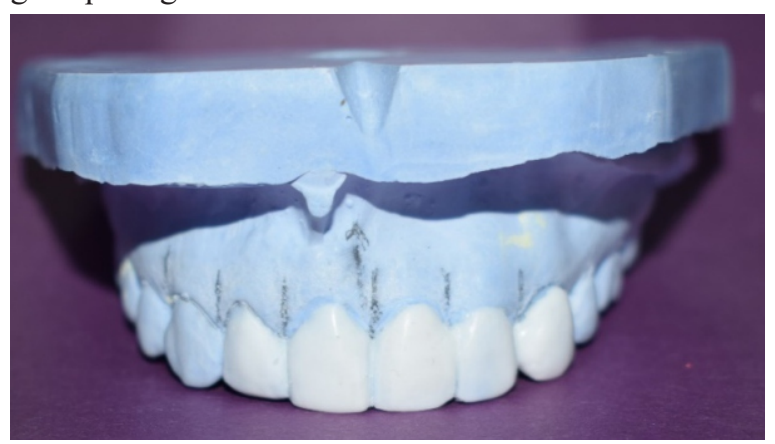

Figura 3. Encerado de diagnóstico

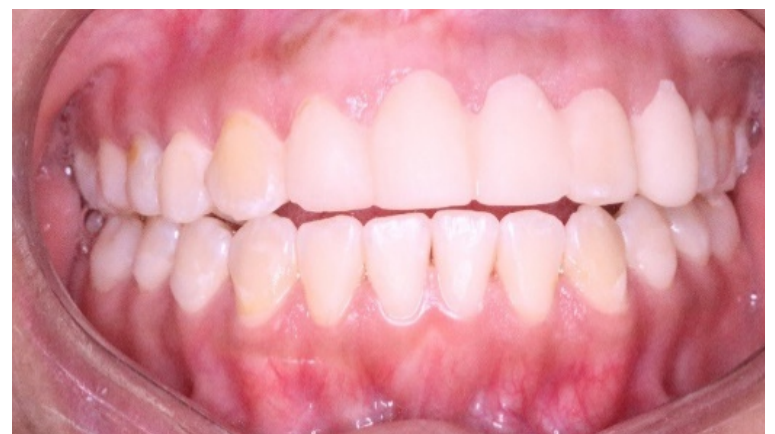

Figura 4. Provicional en bisacril 


\section{Técnica quirúrgica}

Se inicia la cirugía con lidocaína al 2\% 1:100. 000 , se realizó sondaje periodontal para medir el ancho biológico y determinar la posición y altura de la cresta ósea. Se ubicó la guía quirúrgica (Figura 5) sobre la superficie dentaria y se marcó puntos sangrantes de referencia con un explorador. Con un bisturí $15 \mathrm{C}$, se realizó incisión a bisel externo para eliminar el tejido gingival en exceso y con una jacket recta se retiró el tejido. Se continuó con incisión intrasurcular para obtener un colgajo a espesor total de aproximadamente $5 \mathrm{~mm}$., dejando acceso a la cresta alveolar. Se realizó el sondaje periodontal para dejar una distancia de $3 \mathrm{~mm}$ a la unión amelocementaria y preservar el tejido de unión supracrestal. Luego, con una fresa diamantada redonda de diámetro pequeño se procedió a eliminar el hueso alveolar teniendo cuidado de no tocar la superficie radicular hasta conseguir la medida programada sin comprometer la zona de papilas.

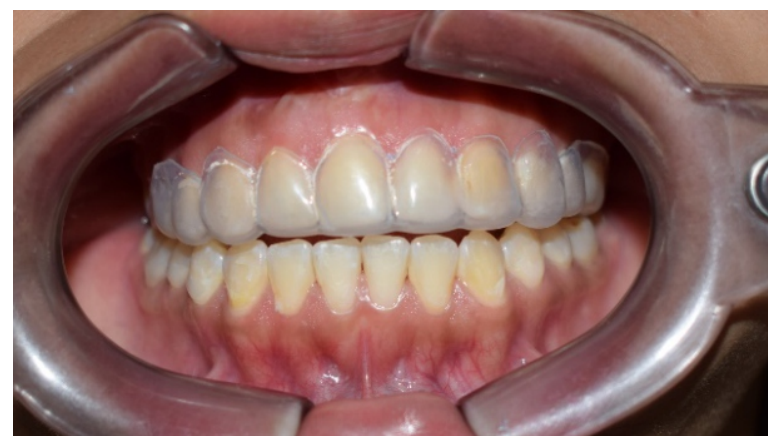

Figura 5. Guía quirúriica

Inmediatamente, se realizó la restauración de las piezas dentarias $(2.1-2.2-2.3)$ con resina de fotoactivación Z350 para dar la nueva forma anatómica de dichas piezas.

Se colocó un apósito de gasa humedecida con clorhexidina presionando el tejido sobre la superficie ósea y el diente para favorecer su adhesión.

Las indicaciones al paciente fueron: Ketorolaco de $10 \mathrm{mg}$ uno cada 8 horas por 3 días y enjuagues de clorhexidina al $0.12 \%$ cada 12 horas durante 10 días. Se realizó el control respectivo a las 24 horas y 7 días de la cirugía. Se observó una buena evolución de los tejidos gingivales y adecuada altura del margen gingival (Figura 6).

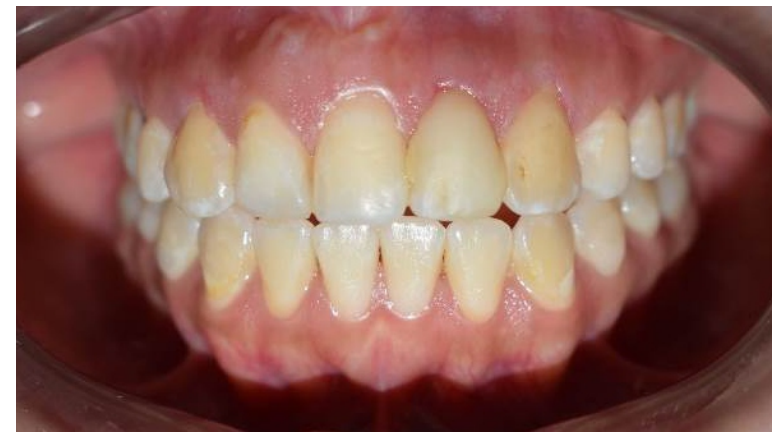

Figura 6. Postoperatorio

\section{Discusión}

Joly (12) presentó un caso en el cual utiliza una técnica mínimamente invasiva sin elevación de colgajo similar a la técnica utilizada por nosotros. El resultado obtenido a 4 meses posteriores a la cirugía mostró un buen estado de los tejidos alrededor de la rehabilitación, lo que sugiere, que utilizar esta técnica es una buena opción para el tratamiento de coronas clínicamente cortas o con defectos de forma dando buenos resultados y con un postoperatorio más tranquilo para el paciente ya que no requiere elevación de colgajo ni colocación de puntos de sutura.

Ribeiro (13) realizó una investigación de 28 pacientes en los que realizó un contraste de la técnica con colgajo de espesor total y sin colgajo para el procedimiento de alargamiento de corona. El autor demostró que ambas técnicas producen resultados clínicos estables a largo plazo y que los pacientes sometidos a tal estudio están conformes con los resultados obtenidos con las distintas técnicas.

Pontoriero y Carnevale (14) estudiaron 84 dientes en 30 pacientes a 12 meses del tratamiento quirúrgico. Los autores encontraron un sobrecrecimiento del margen gingival, por lo que sugieren una tendencia del periodonto a reformar una nueva unidad gingival supracrestal fisiológica.

Deas (15) evaluó 43 dientes en 25 pacientes sometidos a alargamiento coronario quirúrgico, a los 6 meses los resultados demostraron un sobrecrecimiento tisular por lo cual se redujo la altura coronaria a la determinada quirúrgicamente. Esto parece estar relacionado a la altura donde se sutura el colgajo, a las características de cicatrización, a la reformación del ancho biológico y al control personal de placa posquirúrgico.

\section{Conclusión}

En el caso clínico presentado obtuvimos resultados estéticos adecuados a los 10 días del posoperatorio, logrando satisfacer las expectativas del paciente con una técnica mínimamente invasiva con resultados previsibles y sin requerir de técnicas adicionales de mayor complejidad. 


\section{Referencias bibliográficas}

1. Martínez R., Marín G. Cirugía plástica periodontal en coronas clínicamente cortas para rehabilitación protésica. Revista Odontológica Mexicana. 2013;17(4):240-246.

2. Ong M., Tseng S., Wang H. Crown lengthening revisited. Clinical Advances in Periodontics. 2011;1(3):233-239.

3. Gupta G., Gupta R., Gupta N., Gupta U. Crown lengthening procedures - a review article. IOSR-JDMS. 2015;14(4):27-37.

4. Oliveira P., Chiarelli F., Rodrigues J., Shibli J., Zizzari V., Piattelli A., Iezzi G., Perrotti V. Aesthetic surgical crown lengthening procedure. Case Reports in Dentistry. 2015;1-4.

5. Escudero N., García V., Bascones J., Bascones A. Alargamiento coronario, una necesidad de retención protésica, estética y anchura biológica. Revisión bibliográfica. Avances en Odontoestomatología. 2007;23(4):171-180.

6. Majzoub Z., Romanos A., Cordioli G. Crown lengthening procedures: A literatura review. Seminars in Orthodontics. 2014;20(3):188-207.

7. Bennani V., Ibrahim H., Harthi L., Lyons K. The periodontal restorative interface: esthetic considerations. Periodontology 2000. 2017;(74): 74-101.
8. García M. Alargamiento de corona. Rev Mex Periodontol. 2012;3(2):81-86.

9. Tomar N., Bansal T., Bhandari M., Sharma A. The perio-esthetic-restorative approach for anterior rehabilitation. Journal of Indian Society of Periodontology. 2013;17(4):535-538.

10. García S. Alargamiento quirúrgico de coronas clínicamente cortas. Kiru. 2009;6(1):53-56.

11. Hempton T., Dominici J. Contemporary crown-lengthening therapy. A review. JADA. 2010; 141:647-655.

12. Joly J., Mesquita P., Carvalho R. Flapless aesthetic Crown lengthening: a new therapeutic approach. Rev Mex Periodontol. 2011;2(3): 103-108

13. Ribeiro, Hirata, Reis, et al. Open - flap versus flapless esthetic Crown lengthening: 12-month clinical outcomes of a randomized controlled clinical trial. J Periodontol. 2014;85(4): 536544.

14. Pontoriero R, Carnevale G. Surgical Crown lenghtening: a 12-month clinical wound healing study. J Periodontol. 2001; 72: 841-848.

15. Deas DE, Moritz AJ, McDonnell HT, Powell ChA, Mealey BL. Osseous surgery for crown lengthening: a 6-month clinical study. J Periodontol. 2004; 75 (9): 1288-1294.
Correspondencia:

jaimebarcena@hotmail.com
Fecha de recepción : 13 de agosto de 2019

Fecha de aceptación : 09 de noviembre de 2019 